\title{
Cold drawing of 316L stainless steel thin-walled tubes: experiments and finite element analysis
}

\author{
M. Palengat ${ }^{1,2}$, G. Chagnon ${ }^{2, *}$, D. Favier ${ }^{2}$, H. Louche ${ }^{3}$, C. Linardon ${ }^{1,2}$, C. Plaideau ${ }^{1}$ \\ 1 Minitubes, ZAC Technisud, 21 rue J. Vaujany, 38100 Grenoble, France \\ 2 Université de Grenoble/CNRS, Laboratoire 3SR, Cedex 9, 38041 Grenoble, France. \\ 3 Laboratoire de Mécanique et Génie Civil, Université de Montpellier II, 860 route de St. Priest 34090 Montpellier. \\ France
}

\begin{abstract}
Drawing process of thin walled tubes used to fabricate catheters and stents for medical applications was studied. Medical use needs accurate dimensions and a smooth finish of the inner and outer surfaces. This paper deals with 316L stainless steel tubes which are manufactured by means of cold drawing with or without inner plug (mandrel drawing and hollow sinking, respectively). To improve the quality of the finish of the tubes, numerical modelling can be used. In this way, a thermomechanical study of the drawing process is proposed to determine experimentally the physical parameters. This study proposes to evaluate the different parameters of the constitutive equations, of the thermal and friction models using specific experimental tests or using an inverse analysis on the drawing process. These parameters are validated by analysing other tube drawings. Finally the importance of physical parameters fit on drawing limits is emphasised, using a Cockcroft-Latham failure criterion.
\end{abstract}

Keywords: medical device, tube cold drawing, precision metal tubing, friction, thermomechanical modelling, forming limits

\section{Introduction}

Medical instruments, like catheters and stents, are produced by means of thin-walled tubes of small diameter $[1,2]$. Accurate dimensions and very smooth finish of the inner and outer surfaces are two important required qualities for medical instruments. These properties are the results of the quality of the process. Tube drawing process consists in pulling a tube through a conical converging die. Thin-walled tubes are manufactured with this process, reducing progressively inner and outer diameters together with wall thickness.

Drawing process has been analytically studied for several years. Different approaches can be quoted; the first approaches used revolution cones. A first study [3] analysed the deformation of a tube into a conical die but without taking into account the friction. Later, the friction for a die-less drawing was considered [4]. Next, the same type of approaches were developed for polygonal tubes

\footnotetext{
${ }^{*}$ Corresponding author.

Fax: 334768270 43. E-mail: gregory.chagnon@grenoble-inp.fr 
[5]. Many other studies highlighted different points as the repartition of Cockcroft-Latham failure criterion [6], the repartition of the stress into the section [7], the optimisation of a new floating plug [8] or the energy vanished by friction [9].

All these analytical equations lie on simple constitutive equations and do not take into account all the phenomena. In this way, finite element method was used to treat this type of problem. Different studies were proposed, highlighting the importance of physical parameters. The constitutive equation of the material is often an elastoplastic constitutive equation $[10,11,12,13,14,15]$ but few details are given for the parameter fit. Moreover, drawing processes often generate high strain rates [16] and the constitutive equation parameters are fitted on quasi-static experimental data without taking into account the strain rate. Additionally, the deformation of the material generates temperature evolution that should be considered for the modelling of steel material nor shape memory alloys. A last crucial point is the friction between the die and the tube, many authors $[6,17,18,14]$ point out its importance, but very few details are presented to explain the choice of this friction parameter. with the exception of a recent study [15] which used an inverse analysis of tube drawing process to determine the friction coefficient.

At the sight of the importance of the physical parameters of a tube drawing modelling and the lack of literature data, a complete study is proposed in order to present a method to obtain all the physical parameters to well describe an industrial process. This paper focuses on cold drawing, without inner plug and with mandrel, of stainless steel 316L tubes of small diameters (typically of the order of some millimetres). These processes generate temperature variations that are usually not taken into account in tube drawing studies. Experimental measures are realised on drawing benches to evaluate drawing forces and temperature elevations that are generated during different drawing tests. Moreover, it is proposed to evaluate the different parameters (friction coefficient, contact conductivity, inelastic heat fraction) from dedicated experimental tests or by means of an inverse analysis on the industrial process modelling.

This paper is organised as follows. The tube drawing process is explored in section 2. A set of experimental tests was firstly carried out in order to acquire mechanical and thermal data during the drawing process. In section 3 , the physical problem to model is presented. In section 4 , first the material properties implied in the process, such as the anisotropy, the rate-dependence and the temperature-dependence are studied. Shear and tensile tests were performed to determine the 316L stainless steel mechanical behaviour. Second, the convection heat losses and the ratio of plastic work converted into heating were determined by thermal tests. Then, the numerical model is depicted in section 5. Moreover, an inverse analysis is carried out on one drawing test to determine the parameters that have not been determined by simple tests i.e. the friction parameters and thermal conductivity. Finally, in section 6 the influence of the physical parameters on forming limit is studied.

\section{Drawing experiments}

The aim of this part is to completely analyse a drawing process by measuring the applied forces and the temperature variations. In this way, in a first step, the drawing experiments are presented. In a second step, the instrumentation of the drawing bench are detailed and finally temperatures and forces measurements realised on the bench are described. 


\subsection{Tests}

First, a cold tube drawing without inner plug (hollow sinking) was performed as presented in figure 1(a). The outside diameter of one extremity was reduced sufficiently to enter the hole in the

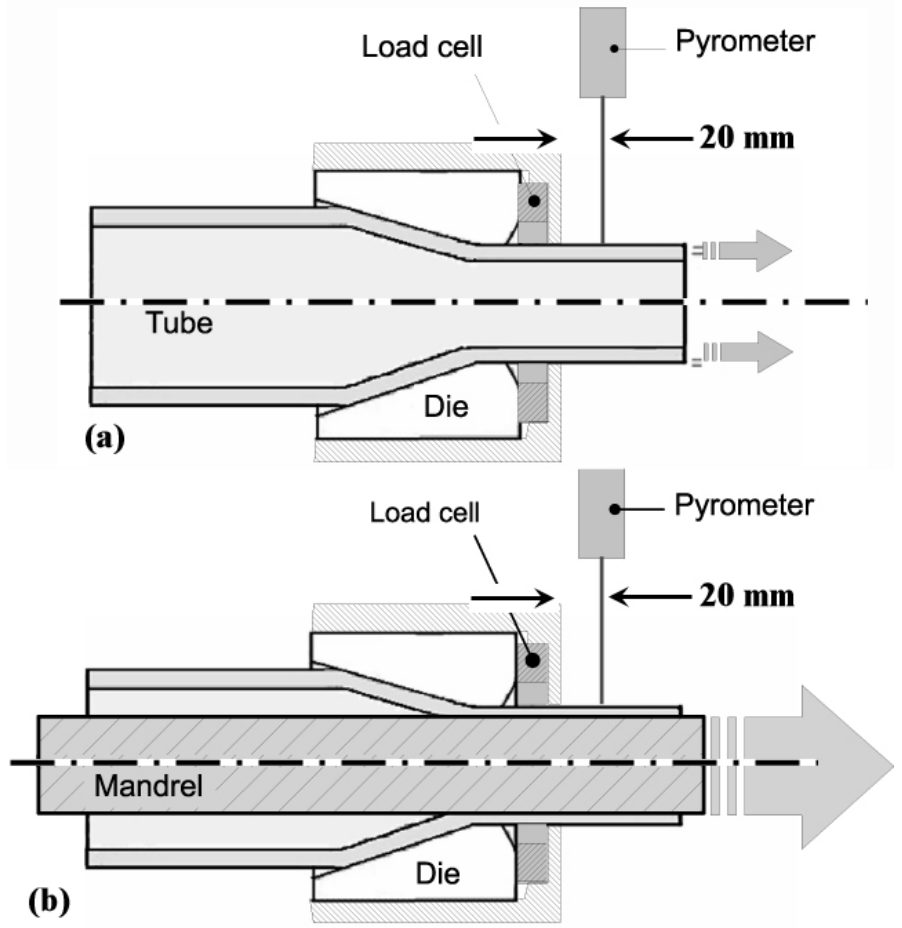

Figure 1: Hollow sinking process (a) and mandrel drawing process (b)

draw die, so that the jaws of the carrier can grip this end of the tube. Then, the tube was pulling through the die at constant speed.

Before drawing, each tube was annealed at $1050^{\circ} \mathrm{C}$. Different drawings were realised and presented next. In the first tests, the outer (OD) and inner (ID) diameters of the tube before drawing were equal to $8.04 \mathrm{~mm}$ and $6.91 \mathrm{~mm}$, respectively. The tubes were drawn through a $6.64 \mathrm{~mm}$ diameter tungsten carbide die, with an entrance angle equal to $17.2^{\circ}$ and a $1.3 \mathrm{~mm}$ bearing. Next, a second set of tests were carried out on these annealed tubes (OD 6.69× ID 4.95) through a 5.22 $\mathrm{mm}$ die with an entrance angle equal to $12.5^{\circ}$ and a $1.1 \mathrm{~mm}$ bearing. Each tube was drawn at three different drawing speeds $\left(6.3 \mathrm{~m} . \mathrm{min}^{-1}, 11.4 \mathrm{~m} . \mathrm{min}^{-1}\right.$ and $\left.15.2 \mathrm{~m} . \mathrm{min}^{-1}\right)$. This represents strain rates about 1 to $10 \mathrm{~s}^{-1}$ when the tube goes through the die. Details of experimental data are listed in table 1. Each test was performed at least four times, to analyse the reproductivity of the experimental data.

Mandrel drawing, presented in figure 1(b), were also performed. The only difference with hollow sinking is that a medium carbon steel mandrel was put inside the tube. Experimental measurements were realised in a similar way as hollow sinking. Tubes (OD 10.5× ID 9.0 and OD $8.16 \times$ ID 7.05) were drawn through 8.13 and $6.64 \mathrm{~mm}$ dies with respectively $7.0 \mathrm{~mm}$ and $5.8 \mathrm{~mm}$ mandrel diameters (details of the tool geometries are reported in table 1). Speeds were the same as in hollow sinking. The strain rates are slightly higher than hollow sinking and are between 1 and $40 \mathrm{~s}^{-1}$. 


\begin{tabular}{|c|c|c|c|c|c|c|c|}
\hline \multirow{2}{*}{$\begin{array}{l}\text { Test } \\
\text { number }\end{array}$} & \multicolumn{2}{|c|}{ Initial Tubes } & \multicolumn{3}{|c|}{ Die } & \multirow{2}{*}{$\begin{array}{c}\text { Mandrel } \\
\varnothing \\
m m\end{array}$} & \multirow{2}{*}{$\begin{array}{l}\text { Speed } \\
\text { m.min }^{-1}\end{array}$} \\
\hline & $\begin{array}{c}\text { Inner } \varnothing \\
m m\end{array}$ & $\begin{array}{c}\text { Outer } \varnothing \\
m m\end{array}$ & $\begin{array}{c}\text { Angle } \\
\text { deg }\end{array}$ & $\begin{array}{c}\varnothing \\
m m\end{array}$ & $\begin{array}{c}\text { Bearing } \\
\mathrm{mm}\end{array}$ & & \\
\hline \multicolumn{8}{|c|}{ Hollow sinking } \\
\hline 1 & 6.47 & 8.04 & 17.2 & 6.64 & 1.3 & / & 6.3 \\
\hline 2 & 6.47 & 8.04 & 17.2 & 6.64 & 1.3 & / & 11.4 \\
\hline 3 & 6.47 & 8.04 & 17.2 & 6.64 & 1.3 & / & 15.2 \\
\hline 4 & 4.95 & 6.69 & 12.5 & 5.22 & 1.1 & / & 6.3 \\
\hline 5 & 4.95 & 6.69 & 12.5 & 5.22 & 1.1 & 1 & 11.4 \\
\hline 6 & 4.95 & 6.69 & 12.5 & 5.22 & 1.1 & / & 15.2 \\
\hline \multicolumn{8}{|c|}{ Mandrel drawing } \\
\hline 7 & 9.0 & 10.5 & 33.0 & 8.13 & 0.3 & 7 & 6.3 \\
\hline 8 & 9.0 & 10.5 & 33.0 & 8.13 & 0.3 & 7 & 11.4 \\
\hline 9 & 7.05 & 8.16 & 22.0 & 6.64 & 2.4 & 5.8 & 6.3 \\
\hline 10 & 7.05 & 8.16 & 22.0 & 6.64 & 2.4 & 5.8 & 11.4 \\
\hline 11 & 7.05 & 8.16 & 22.0 & 6.64 & 2.4 & 5.8 & 15.2 \\
\hline
\end{tabular}

Table 1: Characteristics of the different tests. 1 to 6 : hollow sinking, 7 to 11 : mandrel drawing.

\subsection{Measurements}

The bench was equipped with load and thermal sensors. A load cell located between the die and the die-holder was used to obtain the drawing force. A pyrometer (IP140), fixed after the die exit, recorded the time evolution of the temperature at a spatial point located $20 \mathrm{~mm}$ after the die exit (cf. figure 1). In order for the temperature measurement to be accurate, a calibration of the emissivity parameter of the tube material at the die exit must be performed. For that purpose, the temperature of a tube covered by lubricant was controlled by a fluid circulation (Julabo cryostat) at different temperatures, in the range of $60-130^{\circ} \mathrm{C}$. Figure 2 shows temperature value given by the pyrometer calibrated with an emissivity of 0.15 as function of the true tube temperature. In the following, the tube temperature measurement are corrected using the calibration results.

\subsection{Results}

The drawing force and temperature measured during hollow sinking test number 1 are plotted in figure 3. Such evolutions are representative of all other drawings. In a first stage, when the tube enters in the die, the force increases quickly and reaches its highest value. During the second stage, the force is almost constant. The drawing force decreases instantaneously in the third stage, when the tube exits the die. As the first extremity of the tube is removed from the production, the force peak is not considered. In the following, only the second stage is studied. It is assumed as a mechanical steady state. The drawing force varies with the tube diameters, as it could be expected, but not significantly with the tested drawing speed. Results are listed in table 2 .

Concerning the external temperature, hollow sinking and mandrel drawing lead to different responses. In hollow sinking, the external temperature remains constant all along the pass and does not vary with the drawing speed. In mandrel drawing, the results are different. First, for low speed the temperature remains constant during the test. But for high speed, the temperature along the tube is increasing, Figure 4 shows that no steady state is reached. Moreover, the successive 


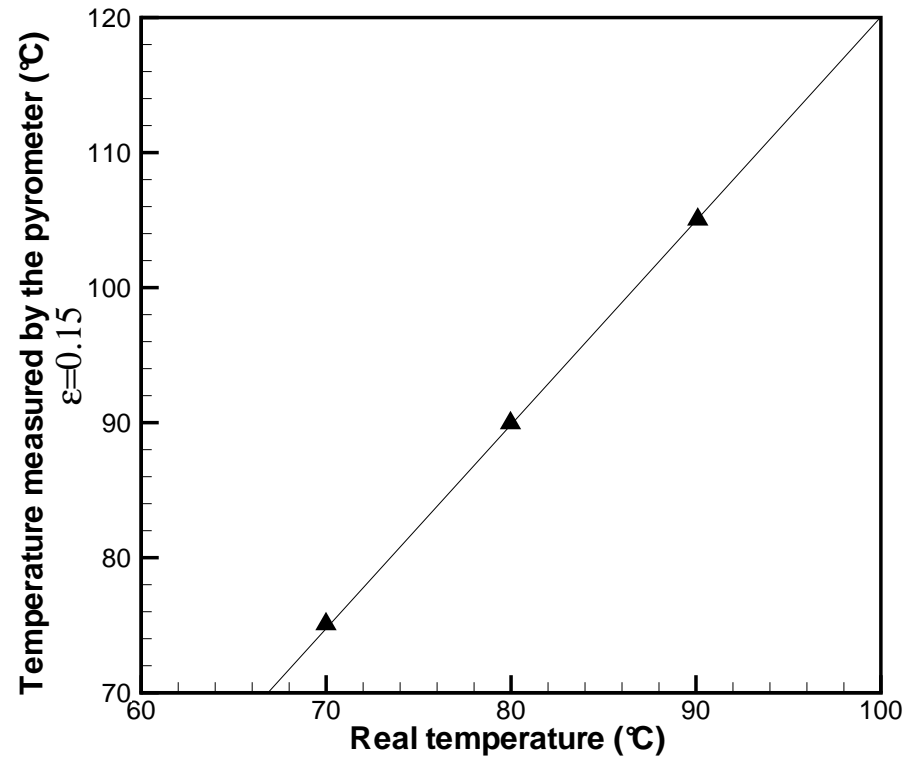

Figure 2: Calibration curve of the pyrometer for a lubricated tube with an emissivity coefficient of 0.15.

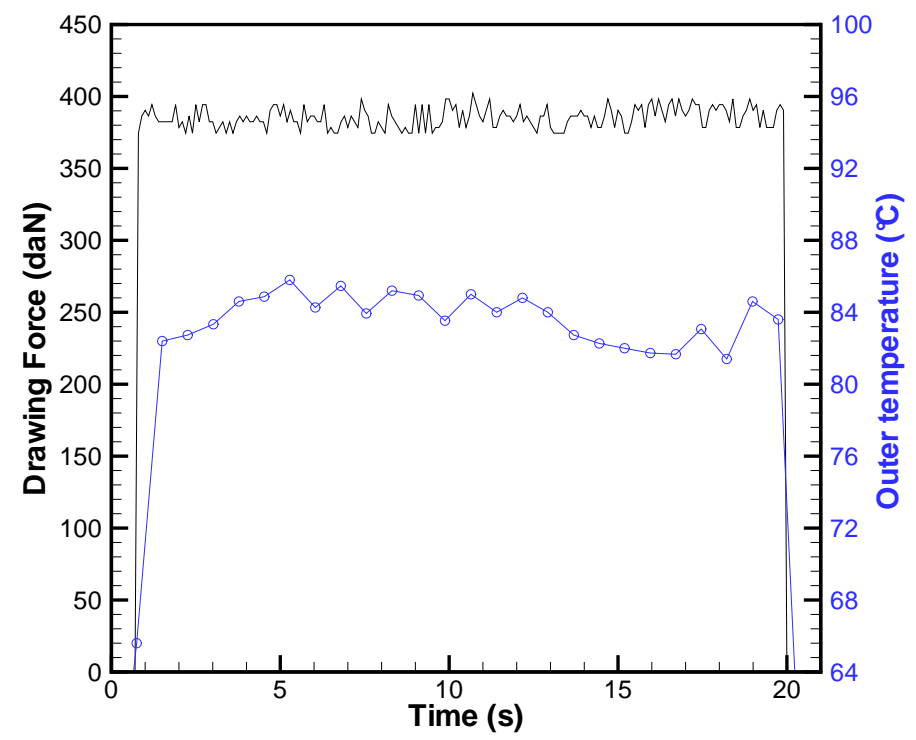

Figure 3: Results of an hollow sinking test. Drawing force (-) and external temperature (-o-) evolutions. The tube enters in the die at $t=1 \mathrm{~s}$, and leaves it at $t=20 \mathrm{~s}$.

mandrel drawing tests were realised every two minutes. A rise of temperature was observed after each test, when the time between tests was short. This was due to the slow cooling of the mandrel and the die between two drawings, which means that initial conditions were not the same for each test. As a consequence, the initial conditions are only known for the first drawing, thus the temperature measures kept for further analysis are listed in the table 2 . 


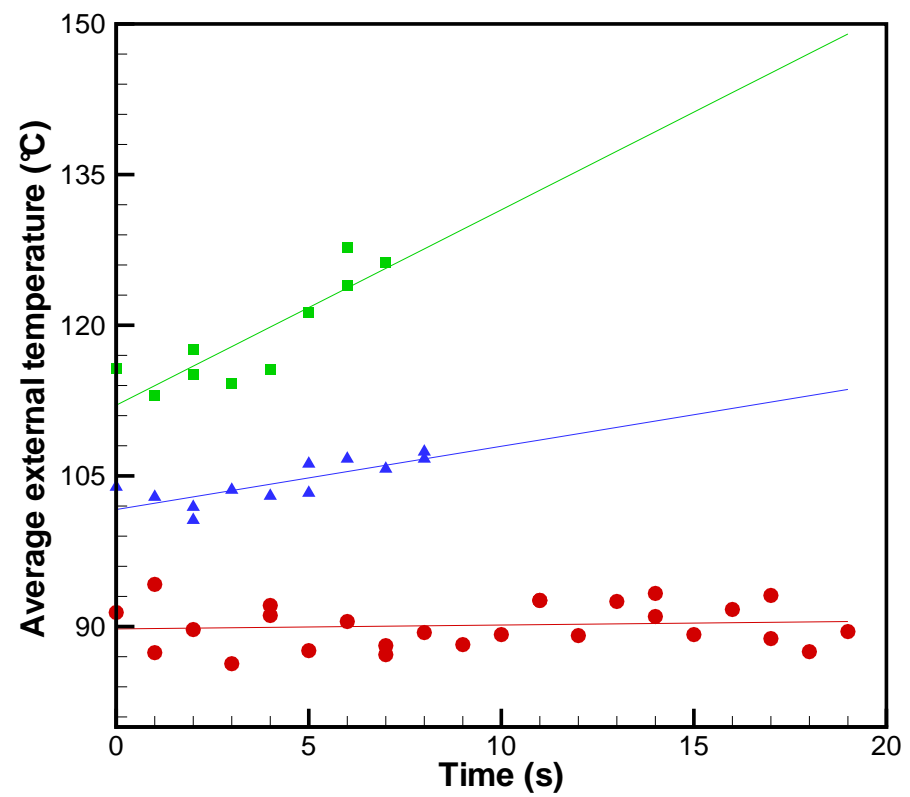

Figure 4: Evolution of the external temperature of a tube during a mandrel drawing for three different speeds: ○ $6.3 \mathrm{~m} \cdot \mathrm{min}^{-1}, \triangle 11.4 \mathrm{~m} \cdot \mathrm{min}^{-1}, \square 15.2 \mathrm{~m} \cdot \mathrm{min}^{-1}$.

\begin{tabular}{lcccc}
\hline $\begin{array}{l}\text { Test } \\
\text { number }\end{array}$ & $\begin{array}{c}\text { Final Tubes } \\
\text { Inner } \varnothing \\
m m\end{array}$ & $\begin{array}{c}\text { Outer } \varnothing \\
m m\end{array}$ & Force & $\begin{array}{c}\text { Outer } \\
\text { temperature } \\
{ }^{\circ} C\end{array}$ \\
\hline \multicolumn{5}{c}{ Hollow sinking } \\
\hline $1,2,3$ & 4.95 & 6.69 & $395 \pm 10$ & $83.0 \pm 2.5$ \\
$4,5,6$ & 3.38 & 5.21 & $381 \pm 10$ & $81.0 \pm 2.5$ \\
\hline \multicolumn{5}{c}{ Mandrel drawing } \\
\hline 7,8 & 7.05 & 8.16 & $995 \pm 25$ & $63.5 \pm 3.0$ \\
$9,10,11$ & 5.90 & 6.74 & $740 \pm 24$ & $80.0 \pm 2.0$ \\
\hline
\end{tabular}

Table 2: Experimental results : mechanical and thermal measurements (mean values obtained by means of at least four tests)

\section{Physical modelling of the drawing}

Drawing process involves large plastic strains due to important diameter reductions (about $30 \%$ ). As a drawing runs quickly, these deformations are reached in a very short time and the strain rates are of the order of 1-40 $s^{-1}$. This leads to high temperature increase. To model this process, first the mechanical study should be done, by means of the local equilibrium equation:

$$
\overrightarrow{d i v} \underline{\underline{\sigma}}=\rho \vec{\gamma}
$$


where $\rho$ is the mass density and $\vec{\gamma}$ the acceleration. Second, the thermal equilibrium is realised by means of the heat equation:

$$
\rho C \frac{\partial \theta}{\partial t}-k \operatorname{Lap} \theta=p_{\text {heat }}
$$

where $\theta=T-T_{0}$ is the temperature variation, $C$ the specific heat, $k$ the thermal conductivity and $p_{\text {heat }}$ the heat sources. Two kinds of heat sources are observed in the drawing operations. One, limited to the contact areas, is linked to the friction phenomenon. The second heat source to be considered in the problem is the intrinsic dissipation due to plasticity.

To solve this problem, the constitutive equation of the different materials (316L for the tube, $\mathrm{WC}$ for the die and medium carbon steel for the mandrel) must be determined by taking into account the influence of the strain rate and of the temperature if necessary. Moreover, as presented in figure 5 by the representation of a drawing process, some interactions must be determined, as

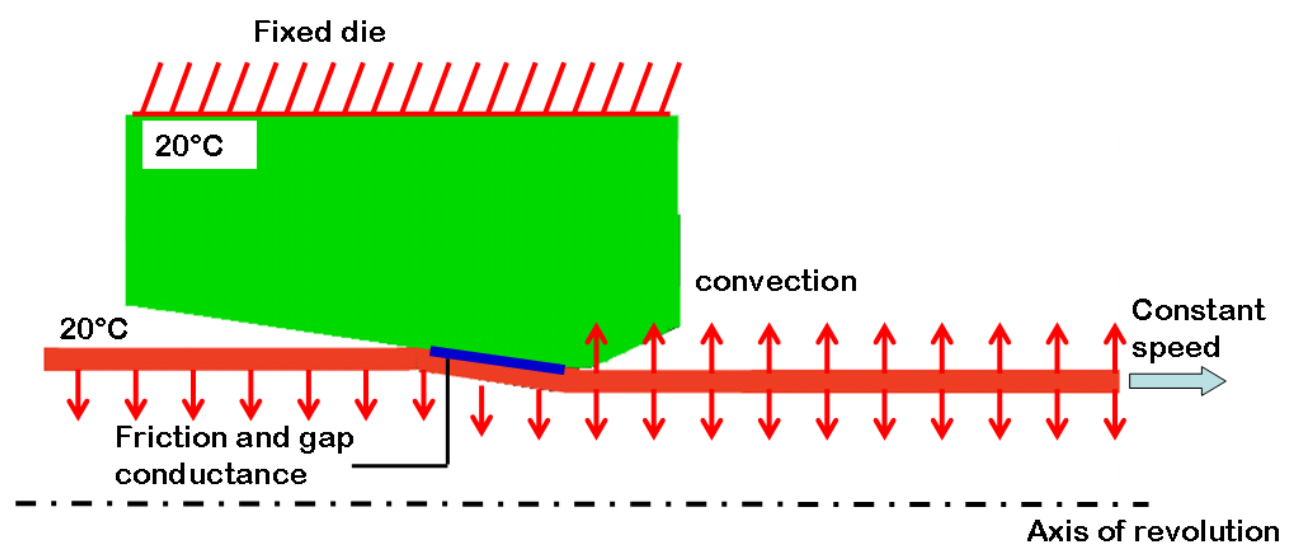

Figure 5: Modelling of the tube drawing process

friction between the tube and the die (and the mandrel and the tube in case of mandrel drawing). Last, convection phenomena after the die exit have to be modelled.

\section{Physical data}

The previous paragraph underlined the different physical parameters that are involved in the tube drawing process. The quality of a thermomechanical modelling is directly linked to the precision of the parameters fit. This part proposes different experimental analysis to fit them.

\subsection{Modelling of the material behaviour}

\subsubsection{Shear and tensile tests on the stainless steel}

The 316L stainless steel mechanical behaviour was studied by means of tensile and shear tests performed at several strain rates. The planar simple shear test has proved to be very efficient to evaluate the mechanical properties of flat samples [19, 20, 21]. The device is designed to impose a parallel displacement of two lateral grips. The resulting displacement is depicted in Figure $6(\mathrm{a})$. To perform these tests, annealed tubes were opened and unwound so that plane sheets were obtained, as shown in Figure 6(b). As unrolling the tubes implies residual stresses in the samples, no constitutive equation may be quantified with these tests. In contrary, anisotropy of 

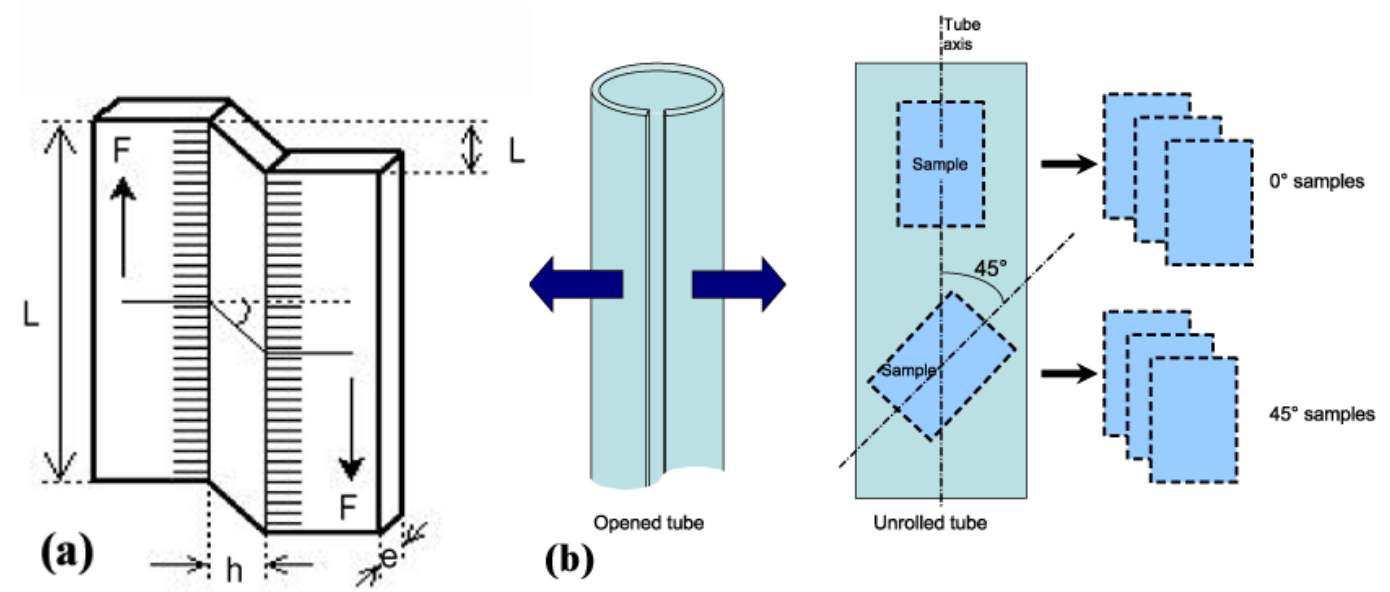

Figure 6: Shear samples: (a) Geometry of a deformed shear sample [20] $h=3 \mathrm{~mm}, e \approx 0.75 \mathrm{~mm}$ and $L=30 \mathrm{~mm}$, (b) Method to obtain shear samples with unwounded tubes.

the unwound tubes is tested. An optical method was used in the present study to observe the strains. The tests were monitored using a digital CCD camera which observes the sample surface covered with a black painting and then with a random pattern of white paint speckles. The local strain field was calculated with the Digital Image Correlation software 7D [22]. First, in order to test the anisotropy of an annealed tube, some samples were cut and sheared with an angle of $45^{\circ}$ to the tube axis (cf. Figure $6(\mathrm{~b})$ ). Three $45^{\circ}$ samples and three $0^{\circ}$ samples were sheared at a strain rate of at $10^{-1} \mathrm{~s}^{-1}$. The response in the two directions are very close as illustrated in Figure 7 , indicating that the material can be assumed as isotropic.

The shear testing device was able to perform strain rates between $10^{-4}$ and $3.10^{-1} \mathrm{~s}^{-1}$, because of the limitations of the testing machine whereas drawing process leads to strain rates between 1 and $40 \mathrm{~s}^{-1}$. To increase the strain rate, tensile tests were realised on another hydraulic tensile machine MTS which can move up to $2 \mathrm{~m} / \mathrm{s}$. This permits to perform the tensile tests in the range $10^{-3} s^{-1}$ to $15 s^{-1}$. The results are presented in Figure 8. They show that the stress increase is about $100 \mathrm{MPa}$ and indicate that quasistatic tests are not appropriate to determine the constitutive equation in this case.

\subsubsection{Constitutive equation of the 316L stainless steel}

The drawing experiments emphasised the temperature increase, but the thermal recordings showed that the tube temperature increase did not exceed $130^{\circ} \mathrm{C}$. As the temperature stays lower than one third of the melting temperature [23] in cold drawing, the material properties do not vary more than $1 \%$ and can therefore be supposed to be independent of the temperature variations.

Previous observations (cf. Figures 7 and 8) indicated that the material behaviour is isotropic and strain rate sensitive. For drawing studies, Sandru and Camenschi [24] proposed a viscoplastic constitutive equation of Bingham type for the high speed drawing with floating plug. Concerning the low carbon steels, different authors $[25,26]$ show that the Johnson-Cook (J.-C) constitutive equation was the most adapted law to model their material behaviour at different strain rates. As the material behaviour is considered temperature-independent, the modified Johnson-Cook law is 


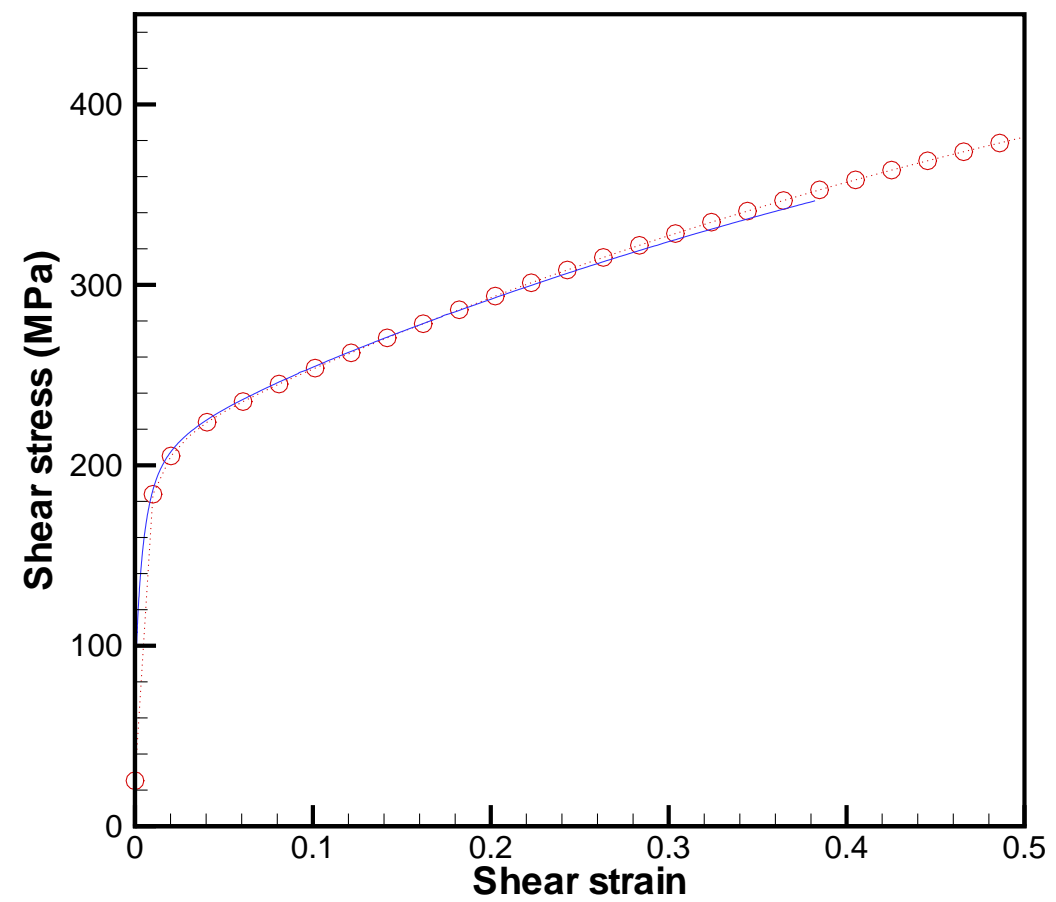

Figure 7: Shear test results : $0^{\circ}$ sample (-) and $45^{\circ}$ responses (o).

used:

$$
\sigma_{e q}=\left(A+B \varepsilon_{e q}^{n}\right)\left(1+D \ln \left(\frac{\dot{\varepsilon}_{e q}}{\dot{\varepsilon}_{e q}^{0}}\right)\right),
$$

where $\varepsilon_{e q}$ represents the equivalent effective plastic strain, $\dot{\varepsilon}_{e q}$ and $\dot{\varepsilon}_{e q}^{0}$ are the effective and the reference plastic strain rates, $A, B, D$ and $n$ are material parameters determined by means of tensile tests (cf. figure 8), they are listed in table 3, the hardening is assumed as isotropic.

\subsubsection{Constitutive equation of the materials of the mandrel and the die}

No irreversible deformation was observed on the die and the mandrel even after many drawings. It is thus considered that their mechanical behaviour stays perfectly elastic during drawing process. Their Young moduli and Poisson ratios are presented in table 3.

\subsection{Modelling of the thermal balance}

\subsubsection{Thermal material parameters}

Thermal properties like conductivity, density and specific heat were easily found in the literature. The values are presented in table 3 for the three materials concerning the process.

\subsubsection{Heat sources}

A major part of the plastic work is dissipated into heat. The remaining part of the plastic work contributes to the storage of internal energy through the creation and rearrangement of crystal 


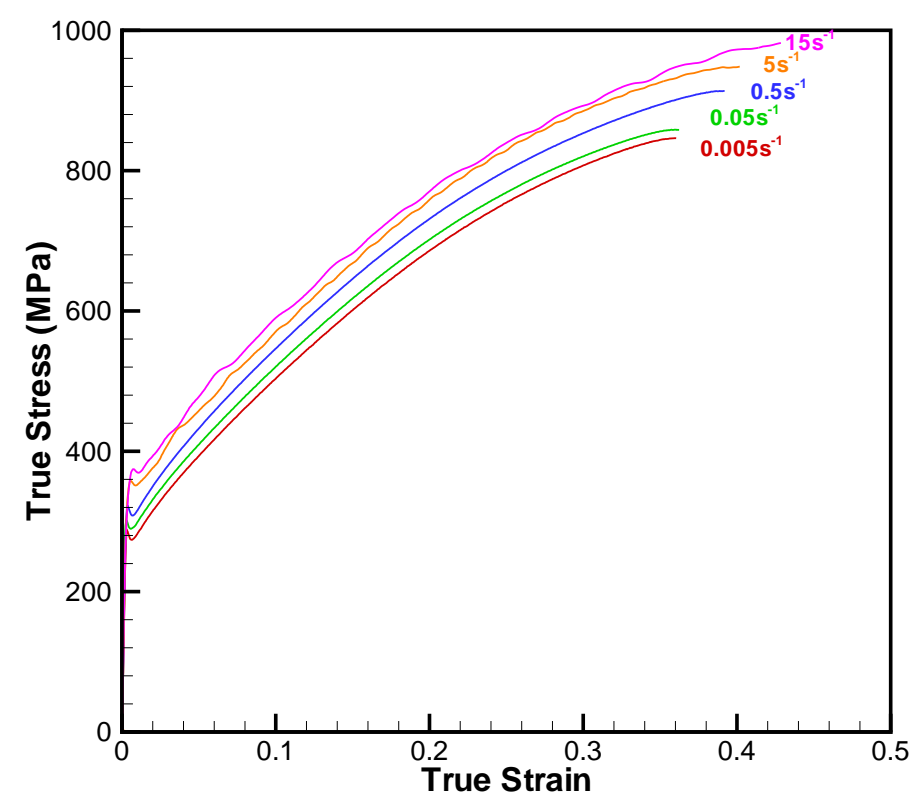

Figure 8: Strain rates sensitivity during tensile tests at $(--) 0.005 s^{-1},(--) 0.05 s^{-1},(-\cdot-) 0.5 s^{-1},(-\cdots-) 5 s^{-1}$ and $(-\cdots-) 15 s^{-1}$.

\begin{tabular}{lccc}
\hline Material & 316L & WC & Medium carbon steel \\
\hline Young's modulus $(G P a)$ & 192 & 650 & 210 \\
Poisson's ratio & 0.3 & 0.2 & 0.29 \\
$\mathrm{~A}(M P a)$ & 242 & $/$ & $/$ \\
$\mathrm{B}\left(M P a^{-1}\right)$ & 1295 & $/$ & $/$ \\
$\mathrm{D}$ & 0.02 & $/$ & $/$ \\
$\mathrm{n}$ & 0.61 & $/$ & $/$ \\
$\varepsilon_{e q}^{0}\left(\mathrm{~s}^{-1}\right)$ & 0.5 & $/$ & 50 \\
Thermal conductivity $\left(W \cdot \mathrm{m}^{-1} \cdot \mathrm{K}^{-1}\right)$ & 16.3 & 10 & 5900 \\
Density $\left(k g \cdot \mathrm{m}^{-3}\right)$ & 7900 & 15000 & $/$ \\
Specific heat $\left(\mathrm{J} \cdot \mathrm{kg}^{-1} \cdot \mathrm{K}^{-1}\right)$ & 500 & 234 & $/$ \\
Convection $\left(W \cdot \mathrm{m}^{-2} \cdot \mathrm{K}^{-1}\right)$ & 8 & $/$ & \\
Inelastic heat fraction & $f\left(\varepsilon_{p l}\right)$ & $/$ & \\
\hline
\end{tabular}

Table 3: Mechanical and thermal properties of the stainless steel 316L, of the tungsten carbide of the die (WC) and of the Medium carbon steel of the mandrel.

imperfections, especially dislocations, but also point defects, stacking faults and twins. This is known as the stored energy of cold work. Starting from the definition of the stored energy of cold work, the inelastic heat fraction is defined as the ratio of the rate of generated heat to the plastic work rate and is called $\beta$. Depending on the authors, its value is traditionally assumed to be a constant taken between $80 \%$ and $100 \%$. Nevertheless, many experimental investigations devoted to plastic deformation have shown the dependence of the inelastic heat fraction on strain, strain 
rate and temperature [29]. Rosakis et al. [28] found that $\beta$ depends strongly on both strain and strain rate for various materials. For example, for an aluminium, for a plastic strain rate of $1 \mathrm{~s}^{-1}$, $\beta$ oscillates around an average value of 0.65 , while for a plastic strain rate of $3.10^{3} s^{-1}$ its average is roughly 0.8 . In conclusion, the inelastic heat fraction $\beta$ must be determined by representative tests of the drawing.

High strain rates tensile tests $\left(\dot{\varepsilon}=1 \mathrm{~s}^{-1}\right.$ ) were realised on $316 \mathrm{~L}$ tube samples (diameter $6 \mathrm{~mm}$, thickness $0.5 \mathrm{~mm}$ ) on a hydraulic high speed MTS tensile machine. Temperature fields at the surface of the sample were recorded during the test with an infrared camera (Cedip Jade III). These fields were uniform in the transverse direction and almost uniform in the axial one. A simplified one dimensional thermal model was then used to estimate the heat sources for a spatial point located in axial position $x$ at current time $t$ as proposed in 2D [27] and also used to study localised phase transformations in NiTi tubes [30]. The problem was assumed to be adiabatic and the heat sources were estimated using:

$$
p_{\text {heat }}(t) \approx \rho C \frac{\partial \theta(x, t)}{\partial t}
$$

Up to maximum load (Considère criterion) the test can be assumed to be uniform. The volumic plastic power $\left(p_{\text {plast }}\right)$ is uniform and can be computed from the mechanical response recorded during the test [31]. Assuming volume conservation during plasticity, the volumic plastic power can finally be estimated with the following relation:

$$
p_{\text {plast }}=\frac{F \dot{U}}{V_{0}}
$$

where $F$ is the force, $V_{0}$ is the initial volume of the specimen and $\dot{U}$ is the cross head velocity. Figure 9 displays the volumic plastic power, the volumic heat power and their ratio $\beta$ measured during a tensile test at a strain rate of $1 \mathrm{~s}^{-1}$. It appears that $\beta$ is strain dependent. Starting at about $40 \%$, it increases slowly up to about $90 \%$ at maximum load $\left(\varepsilon_{p}=0.2\right)$.

\subsection{Thermal and mechanical contacts}

\subsubsection{Friction behaviour}

Friction is a highly complex phenomenon. A commonly used technique to study contact properties is the pin-on-disk test. As the name implies, such apparatus consists essentially of a pin in contact with a rotating disc. This test is standardised [32]. However, in bulk metal forming, ring compression test is widely used for evaluating friction coefficients [33, 34]. The effect of material properties, strain-rate sensitivity and barrelling on the behaviour of friction calibration curves obtained from the ring compression test was investigated [35]. Although this test is widely used, the use of generalised friction calibration curves is impossible as each material and process condition needs a new test curve. Other approaches based on inverse methods are also proposed (see [36] for example). Such class of method is chosen in our study to estimate a Coulomb model. It is presented in the part 5.2.

Moreover, it is considered that the whole generated energy created by friction is converted into heat. In a first approach it can be considered that the energy is equally transferred to the tube and to the die. 


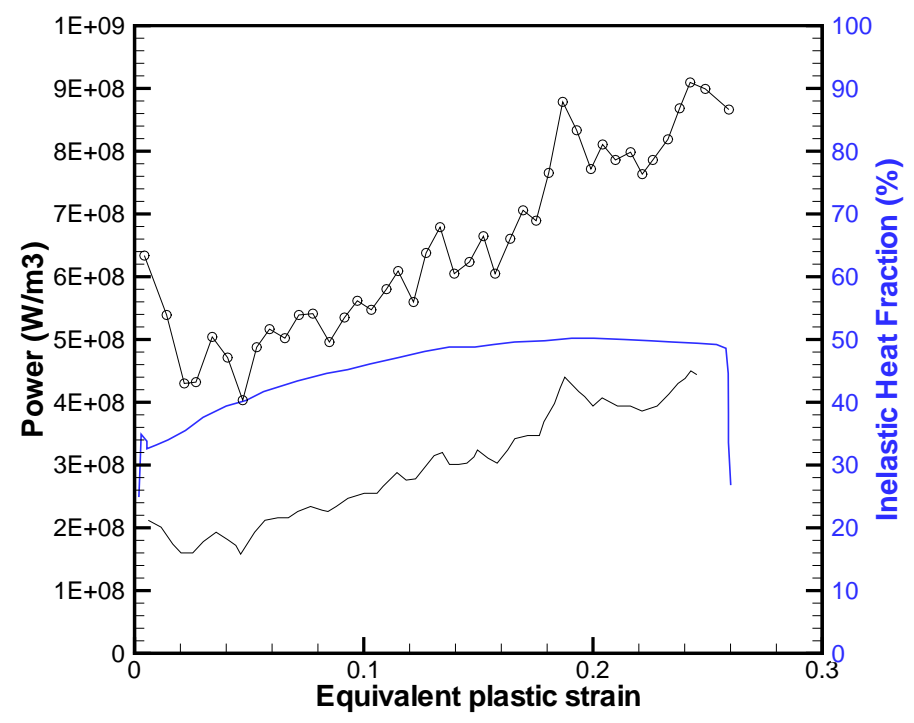

Figure 9: Evaluation of the inelastic heat fraction (o) by means of the ratio of the heat power $(-)$ and the plastic work rate $(--)$, for a tensile test at $10^{-1} s^{-1}$.

\subsubsection{Convection heat transfert coefficient}

As proposed in a forging process [37], the same methodology was used to determine the convective heat transfert coefficient. A tube was placed in a oven until its temperature reaches $180^{\circ} \mathrm{C}$. Then it was put outside of the oven and its natural cooling was recorded with a thermocouple. A finite difference scheme enabled to solve the heat equation and to find the convective heat transfert coefficient: $h=8 \mathrm{~W} \cdot \mathrm{m}^{-2} \cdot \mathrm{K}^{-1}$.

\subsubsection{Thermal gap conductance}

A last contact parameter is the thermal gap conductance which can depend on several parameters. The dominant ones are the kind of contacting materials, the macro- and micro-geometry of contacting surfaces, the temperature of the materials, the interfacial pressure and lubricant and/or surface contaminants and the thickness of the interfacial layer. A review of existing experimental methods for the thermal contact conductance measurement under conditions that replicate metalforming operations is presented in [38]. The typical experimental equipment for measuring thermal contact conductance under steady-state conditions consists of two geometrically identical cylinders, which are in contact at their flat surfaces, and are subjected to an axial force. Axial heat flow is achieved by applying a heat source at one free end of the cylinders while a heat sink draws the heat across the interface from the opposite end of the other cylinder. Thermal conductance is then derived from the temperature measurements. Unfortunately, to the best of our knowledge, there is no published results for the $316 \mathrm{~L}$ stainless steel in the $20-120^{\circ}$ temperature range. This parameter will be identified by means of an inverse analysis proposed in the part 5.2.

\section{Finite Element Analysis}

The aim of this part is to perform numerical simulation of hollow sinking and mandrel drawing. First, the laking parameters (friction coefficient and thermal conductance) are identified by means 
of a finite element inverse analysis on experimental data of one industrial drawing test. Second, the different drawings listed in table 1 are simulated with the identified parameters.

\subsection{Model}

Finite element models were built in the industrial Finite Element software Abaqus/Explicit. As material behaviour, geometry and loading conditions are considered as axially symmetric, an axisymmetric model was used. 4-node thermally coupled axisymmetric quadrilateral, bi-linear displacement and temperature, with reduced integration and with hourglass control elements (CAX4RT), were chosen. At least 8 elements are used in the thickness of the tube, all elements are chosen to be close to a square in non deformed configuration. This mesh was chosen to ensure a good accuracy of the results without being too time consuming. It ensures results that are independent of the mesh even if in singular points, some differences can be noted. From a mechanical point of view, the steady-state condition is the dominating phase in tube drawing. However, as the model is coupled in temperature and displacement, a transient analysis was used. Besides, the lubrication was supposed homogeneous and constant during the process. Thus, variations in lubrication were not taken into account and only a constant Coulomb coefficient was used to model friction.

Boundary conditions chosen for the model are those presented in figure 5. Dies are fixed and the tube is drawn at a constant speed equal to the mean velocity measured during the experiments. The displacement boundary conditions are applied on the extremity of the tube or on the mandrel when it is used. Thermal losses are imposed on the tube surface with the natural convection exchange. Tubes and tools are initially at room temperature. Heat generated by friction is distributed equally between the tube and the die. A constant gap conductance is defined between the tube and the die.

Abaqus Explicit software needs a constant inelastic heat fraction $\beta$ whereas experimental results showed that it evolves (cf. Figure 9). A mean $\beta$ (noted $\bar{\beta}$ ) was then computed in order to obtain the same heat energy as in the non constant case:

$$
\int_{0}^{t_{f}} \bar{\beta} p_{\text {plast }}(M, t) d t=\int_{0}^{t_{f}} \beta(t) p_{\text {plast }}(M, t) d t
$$

and so:

$$
\bar{\beta}=\frac{\int_{0}^{t_{f}} \beta(t) p_{\text {plast }}(M, t) d t}{\int_{0}^{t_{f}} p_{\text {plast }}(M, t) d t}
$$

where $\mathrm{M}$ is a material point and $t_{f}$ a time. Choosing a point $\mathrm{M}$ and a time $t_{f}$ where plastic strain increased up to maximum load (about 0.2 noted in Figure 9) led to a constant value equal to 0.6 for $\bar{\beta}$.

\subsection{Inverse analysis}

An inverse analysis was carried out using the data of the first experiments in order to identify the friction and thermal parameters. These parameters are not easy to fit and are strongly dependent on process (lubrication, tool surfaces, ...). It is thus better to identify them on drawing benchs.

This parameter identification strategy is based on two remarks. First, once the constitutive equation is determined, the drawing force depends mainly on the friction coefficient. Secondly, the external temperature depends both on heat generation (plasticity and friction) and thermal 
exchanges (in the tube, in the die, at the interface and at the outer surfaces). Hence the heat induced by the plasticity remains constant. After a first step, where the friction coefficient is chosen in order to obtain the measured drawing force, a second step is proposed to identify the thermal conductance. As parameter identification is decomposed into two steps without identifying several steps at the same time, an inverse analysis is carried out.

\subsection{Results}

First, the friction and thermal parameters are fitted on experimental tests, on an hollow sinking for the friction parameter - test $\mathrm{n}^{\circ} 1$, and the thermal parameter on a mandrel drawing - test $\mathrm{n}^{\circ} 7$ (cf. table 1). Thermal gap conductances were assumed to be the same between the die and the tube and between the tube and the mandrel. The obtained values are respectively 0.07 for the friction parameter and $100 \mathrm{~kW} \cdot \mathrm{m}^{-2} \cdot \mathrm{K}^{-1}$ for the thermal gap conductance. These values are then used to simulate the other drawings, with the hypothesis that the friction coefficient and the contact conductance are the same for all the tests.

The different tests presented in table 1 are simulated. The predicted force and the external temperature are compared with experimental results in figure 10. As expected, the drawing force is quite well described.
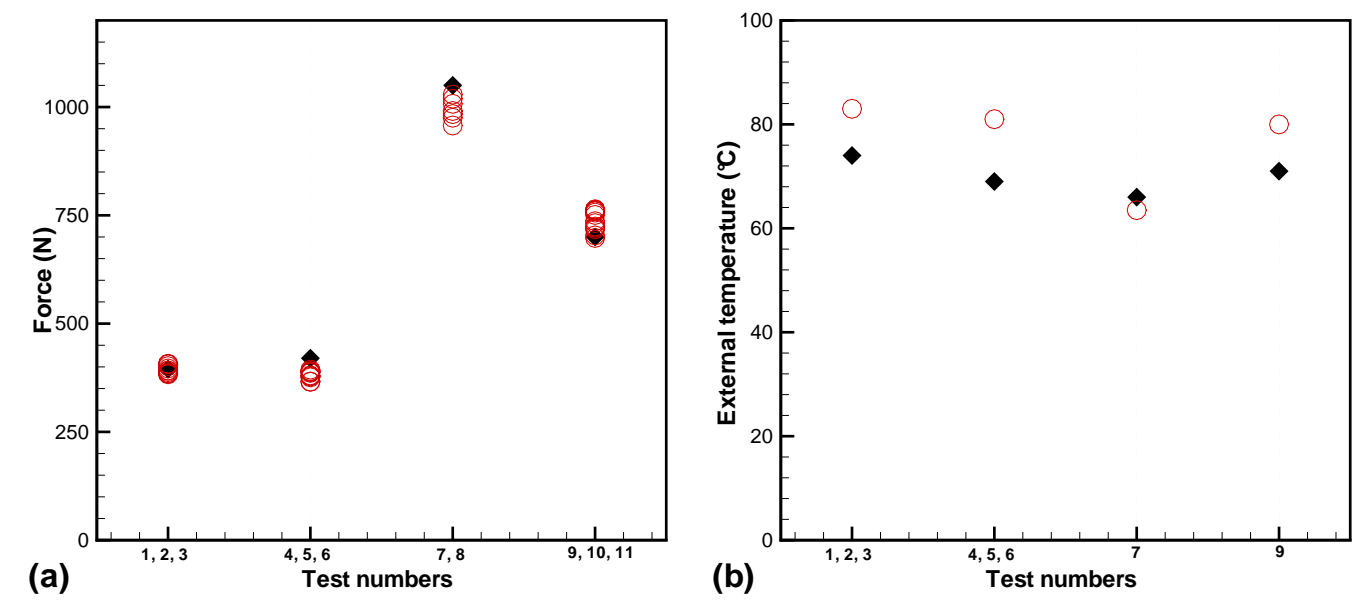

Figure 10: Comparison of the experimental results $\circ$ with finite element simulation $\downarrow$ for (a) the drawing force and (b) the temperature rise.

For the temperature predictions, only the first test is presented for each bench test series. It appears that the external temperatures predicted by the model underestimate (about ten degrees) the measured ones. This difference can be due to different hypotheses of the model. As no experimental thermal measure could be done, it was supposed that heat generation by friction was decomposed into two equal parts into the tube and the die. By imposing all the heating going into the die or into the tube, the temperature variation changes are only about 2 or 3 degrees. An important point, that was not tackled in the study is the influence of the lubrication with the thermal effect of the lubricant used during the drawing. Moreover, it is very difficult to identify the proper boundary conditions for an industrial process. Nevertheless, the results are very encouraging as many parameters were experimentally determined, and force prediction are very good. The figure 11 presents the value of the triaxiality ratio for the tube inside the die for 

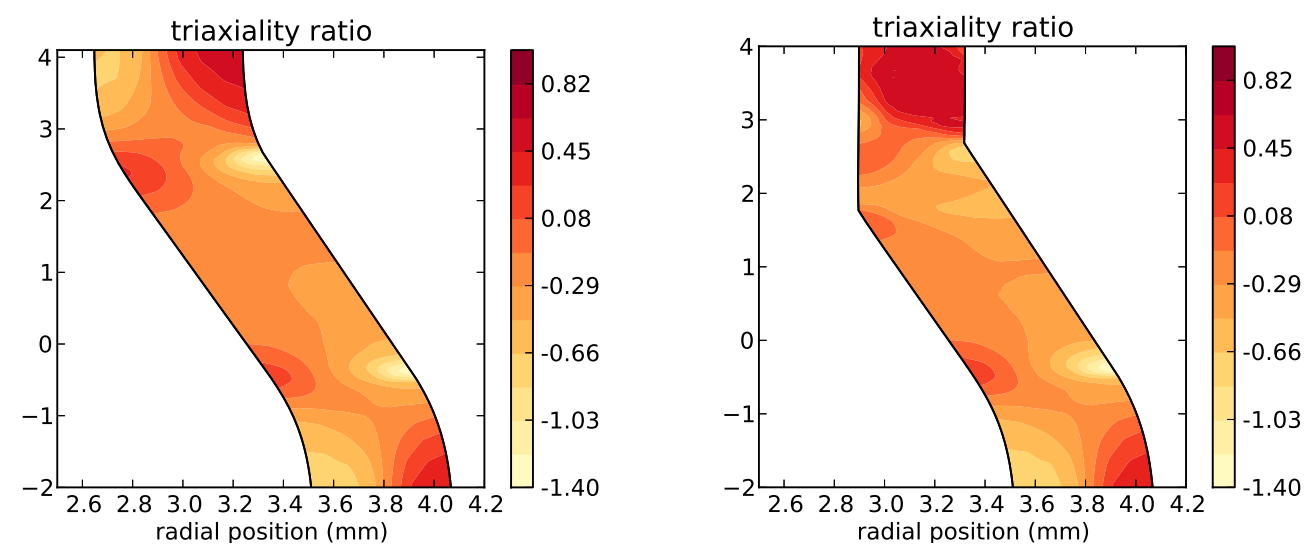

Figure 11: Triaxiality ratios inside the tube for an hollow sinking and a mandrel drawing.

an hollow sinking and a mandrel drawing. It appears that the loading state is very heterogeneous in the tube. The triaxiality profiles are quite similar at the beginning of the drawing process i.e. the bottom of the figure, whereas the triaxiality ratios are different when the tube is near the exit of the die, i.e. top of the figure. This is due to the presence of the mandrel which applies a force inside the tube. Thus for mandrel drawing, the loading state is quite equivalent to uniaxial extension whereas it is very heterogeneous for the hollow sinking. This means that they cannot be considered as the same experimental test. They are two complementary experiments that can be used to test some criteria.

\section{Forming limits in the tube drawing process}

One way to improve the manufacturing process is to reduce the number of drawings by optimising the section reduction during each drawing step. To do it, one must use forming limits criteria of the material. Many different forming limit criteria were proposed in the literature [39], most of them for stamping or moulding, no specific criterion was developed for tube drawing. In a first approach, the Cockcroft-Latham failure criterion, noted $C_{\text {process }}$ [6] is used in this paper. Its value is evaluated along the tube thickness for different drawings, by means of the integration of the maximal principal stress $\sigma_{1}$ on the equivalent plastic deformation during the drawing:

$$
C_{\text {process }}=\int_{0}^{\bar{\varepsilon}_{f}} \sigma_{1} d \bar{\varepsilon}
$$

where $\bar{\varepsilon}_{f}$ is the maximal plastic equivalent deformation reached during the drawing. Plastic equivalent deformation and principal maximal stress are presented in figure 12. It clearly appears that the profile of stress and strain are very different for hollow sinking and mandrel drawing. The maximum stress does not appear at the same place in the two cases, as well as, the gradient of equivalent plastic strain. Moreover, for mandrel drawing, strain and stress distributions are strongly depending on the die bearing length Ldb (see arrows in figure 12). Evolutions of the Cockcroft-Latham failure criterion, for the three different drawings and for three different friction parameter values are presented in Figure 13. The limit value of the criterion was identified by means of the tensile test realised in Part 4 . The curve at $15 \mathrm{~s}^{-1}$ was chosen as it is the closest strain 
rate to those reached during drawing process. It clearly appears that the values for this criterion are quite different according to the drawing type. For hollow sinking, the loading seems to be the same on the whole thickness, whereas for mandrel drawing, a heterogeneity is observed. Moreover, thickness distribution of the criterion is different in these two mandrel drawing processes. The variations of criteria are larger between inner and outer diameters for the second mandrel drawing than during the first one. As the section reductions are similar, the main difference between the two mandrel drawings is the length of the die bearing. The contact properties in the bearing area modify the plastic strain distribution in and along the tube thickness and thus the forming limit. It also clearly appears that the values of the forming limit criteria are not proportional to the friction coefficient values. Thus, a numerical simulation is needed to obtain the forming limit criteria when the friction parameter changes. The results are quite dependent on the values of each physical parameter (including the friction parameter, ...), that proves that the identification of each physical coefficient is a key point for the tube drawing improvement.

\section{Conclusion}

The paper presented a complete analysis of an industrial drawing process. An instrumentation of the industrial bench permitted to measure the forces and temperatures during each drawing. An objective of the paper was to be able to model this drawing process. In this way specific experimental tests were developed to identify the constitutive equation, the inelastic heat fraction, the convection heat transfers. An inverse analysis was conducted on one drawing test to identify the friction parameter and the thermal gap conductance. All these parameters were used to simulate different drawing tests. Force values were correctly predicted. For the temperature, a ten degrees difference was observed and can be due to the following hypotheses made in this study. First, the lubrication was not taken into account and second, it was considered that only half of the heating was transferred into the tube.

Even if there were some differences in the temperature predictions, the finite element model allowed to schedule a fine analysis of the local temperature and stress-strain states to evaluate forming limit of the material for different diameter reductions. The profile of the forming limit emphasised that, in hollow sinking as in mandrel drawings, the phenomena were quite different in the inner or outer diameter. Moreover, for two mandrel drawings with two different die geometries the differences were quite important. A particular attention must be focused on the temperature variation and on the interface properties of the tube with the tools. These different conditions affect largely the local behaviour of the material and thus its limit properties, as presented for the friction parameter. This emphasises that the identification of the whole physical parameters is a key point of the modelling. Their values directly affect the results of the simulations and should be experimentally determined.

\section{References}

[1] Poncin, P., Ferrier, D., Loshakove, A., Proft, J., and Meyer-Kobbe, C. (May 2001). A comparison between two manufacturing methods. In A. P. S. Russell, editor, Proceedings International Conference on Shape Memory and Superelastic Technologies, Asilomar, California, page 477.

[2] Favier, D., Liu, Y., Orgeas, L., Sandel, A., Debove, L., and Comte-Gaz, P. (2006). Influence of thermomechanical processing on the superelastic properties of a Ni-rich nitinol shape memory alloy. Mat. Sci. Eng. A-Struct., 429, $130-136$.

[3] Um, K. and Lec, D. N. (1997). An upper bound solution of tube drawing. J. Mater. Proc. Technol., 63, 43-48. 
[4] Wang, Z. T., Luan, G. F., and Bai, G. R. (1999). Study of the deformation velocity field and drawing force during the dieless drawing of tube. J. Mater. Proc. Technol., 94, 73-77.

[5] Bayoumi, L. S. (2001). Cold drawing of regular polygonal tubular sections from round tubes. Int. J. Mech. Sci., 43, $2541-2553$.

[6] Karnezis, P. and Farrugia, D. C. J. (1998). Study of cold tube drawing by finite-element modeling. J. Mater. Proc. Technol., 80-81, 690-694.

[7] Dai, K., and Wang, Z. R. (2000). A graphical description of shear stress in the drawing of a thin-wall tube with a conical die. J. Mater. Proc. Technol., 102, 174-178.

[8] Swiatkowski, K., and Hatalak, R. (2004). Study of the new floating-plug drawing process of thin-walled tubes. J. Mater. Proc. Technol., 151, 105-114.

[9] Rubio, E. M., Camacho, A. M., Marcos, M., and Sebastian, M. A. (2008). Analysis of the energy vanished by friction in tube drawing processes with a fixed conical inner plug by the upper bound method. Mater. Manufact. Process., 23, 690-697.

[10] Shimmin, E. W., and Oxley, P. L. B. (1983) Some numerical slipline field solutions for drawing through circular dies. Int. J. Mech. Sci., 25, 785-802.

[11] Lee, Y. S., and Hahm, S. Y., (1983) Mechanical property changes in drawing extrusion of hardening viscoplastic materials with damage. Int. J. Mech. Sci., 39, 565-573.

[12] Yoshida, K. and Furuya, H. (2004). Mandrel drawing and plug drawing of shape-memory-alloy fine tubes used in catheters and stents. J. Mater. Proc. Technol., 153, 145-150.

[13] Kim, S. W., Kwon, Y. N., Lee, Y. S., and Lee, J. H. (2007). Design of mandrel in tube drawing process for automotive steering input shaft. J. Mater. Proc. Technol., 187, 182-186.

[14] Kuboki, T., Nishida, K., Sakaki, T., and Murata, M. (2008). Effect of plug on levelling of residual stress in tube drawing. J. Mater. Proc. Technol., 204, 162-168.

[15] Béland ,J.-F., Fafard, M., Rahem, A., D'Amours, G., and Côté, T. (2011). Optimization on the cold drawing process of 6063 aluminium tubes. Appl. Math. Model., 35, 5302-5313.

[16] Cristescu, N. (1976) Drawing through conical dies An analysis compared with experiments. Int. J. Mech. Sci., 18, 45-49.

[17] Li, M. Q., Sun, Z. C., Li, M. H. and Yang, H. (2005). FEM numerical simulation of tube axial drawing process. J. Mater. Proc. Technol., 160, 396-400.

[18] Lee, S. K., Ko, DZ. C., Kim, B. H., Lee, J. H., Kim, S. W. and Lee, Y. S. (2007). A study on monobloc tube drawing for steering input shaft. J. Mater. Proc. Technol., 191, 55-58.

[19] Manach, P.-Y. and Favier, D. (1997). Shear and tensile thermomechanical behavior of near equiatomic NiTi alloy. Mat. Sci. Eng. A-Struct., 222, 45-57.

[20] Rauch, E. (1998). Plastic anisotropy of sheet metals determined by simple shear tests. Mat. Sci. Eng. A-Struct., 241, 179-183.

[21] Thuillier, S. and Manach, P. Y. (2009). Comparison of the work-hardening of metallic sheets using tensile and shear strain paths. Int J Plast, 25, 733751.

[22] Vacher, P., Dumoulin, S., Morestin, F., and Mguil-Touchal, S. (1999). Bidimensional strain measurement using digital images. Instn Mech Engrs Part C ImechE, 213, 811-817.

[23] Lemaitre, J. and Chaboche, J.-L. (1994). Mechanics of solid materials. Cambridge University Press.

[24] Sandru, N. and Camenschi, G. (1988). A mathematical model of the theory of tube drawing with floating plug. Int. J.Eng. Sci., 26, 569-585.

[25] Fréchard, S., Redjaïma, A., Metauer, G., Lach, E., and Lichtenberger, A. (2002). Comportement dynamique et évolution microstructurale d'un acier austénitique allié à l'azote. In Matériaux 2002, Tours, France.

[26] Umbrello, D., M'Saoubi, R., and Outeiro, J. (2007). The influence of Johnson-Cook material constants on finite element simulation of machining of AISI 316L steel. Int. J. Mach. Tool. Manu., 47, 462-470.

[27] Chrysochoos, A. and Louche, H. (2000). An infrared image processing to analyse the calorific effects accompanying strain localisation. Int. J. Engrg Sci., 38, $1759-1788$.

[28] Rosakis, P., Rosakis, A. J., Ravichandran, G., and Hodowany, J. (2000). A thermodynamic internal variable model for the partition of plastic work into heat and stored energy in metals. J. Mech. Phys. Solids, 48, 581-607.

[29] Chrysochoos, A., Maisonneuve, O., Martin, G., Caumon, H., and Chezeaux, J. C. (1989). Plastic and dissipated work and stored energy. Nucl Eng Design, 114, 323-333.

[30] Schlosser, P., Louche, H., Favier, D., and Orgéas, L. (2007). Image processing to estimate the heat sources related to phase transformations during tensile tests of NiTi tubes. Strain, 43, 260-271.

[31] Dumoulin, S., Louche, H., Hopperstad, O. S., and Borvik, T. (2010). Heat sources, energy storage and dissipation in high strength steels: Experiments and modelling. Eur. J. Mech. A-Solids, 29, 461-474. 
[32] ASTM G99 (2005). Standard test method for wear testing with a pin-on-disk apparatus. Technical report, ASTM International.

[33] Kunogi, M. (1956). A new method of cold extrusion. J. Sci. Research Inst., 50, 215-246.

[34] Male, A. T. and Cockcroft, M. G. (1964). A method for the determination of the coefficient of friction of metals under condition of bulk plastic deformation. J. Inst. Met., 93, 38-46.

[35] Sofuoglu, H., Gedikli, H., and Rasty, J. (2001). Determination of friction coefficient by employing the ring compression test. J. Eng. Mater-T. ASME, 123, 338-348.

[36] Lazzarotto, L., Dubar, L., Dubois, A., Ravassard, P., and Oudin, J. (1997). Identification of Coulomb's friction coefficient in real contact conditions applied to a wire drawing processes. Wear, 221, 54-63.

[37] Polozine, A. and Schaeffer, L. (2005). Exact and approximate methods for determining the thermal parameters $f$ the forging process. J. Mater. Proc. Technol., 170, 611-615.

[38] Rosochowska, M., Chodnikiewicz, K., and Balendra, R. (2004). A new method of measuring thermal contact conductance. J. Mater. Proc. Technol., 145, 207-214.

[39] Venugopal Rao, A., Ramakrishnan N., and Krishna kumar, R. (2003). A comparative evaluation of the theoretical failure criteria for workability in cold forging. J. Mater. Process. Technol., 142, 29-42. 


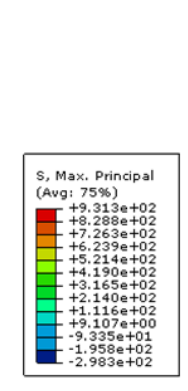

(a)
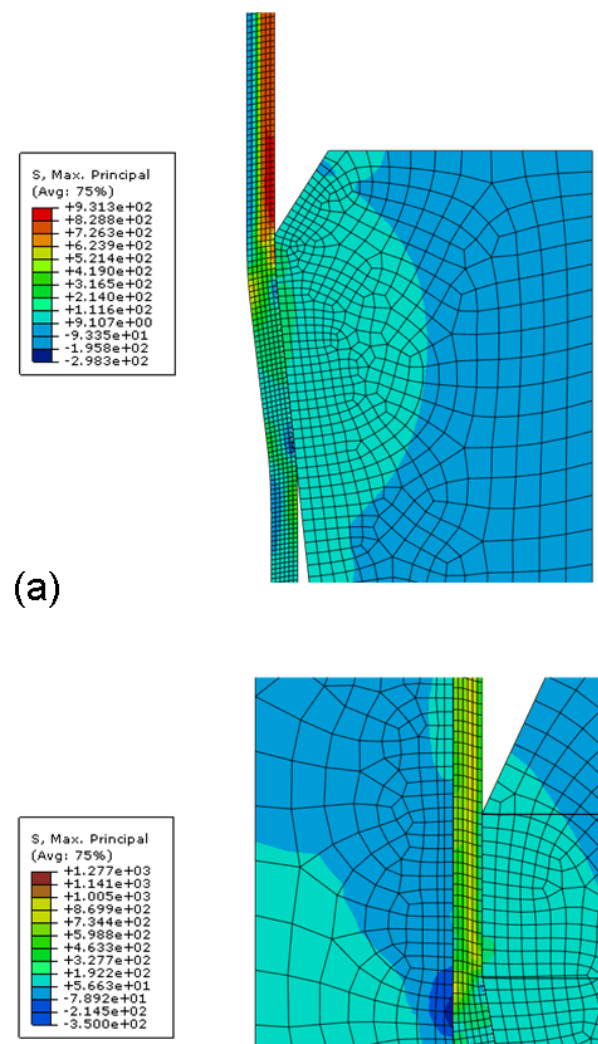

(c)
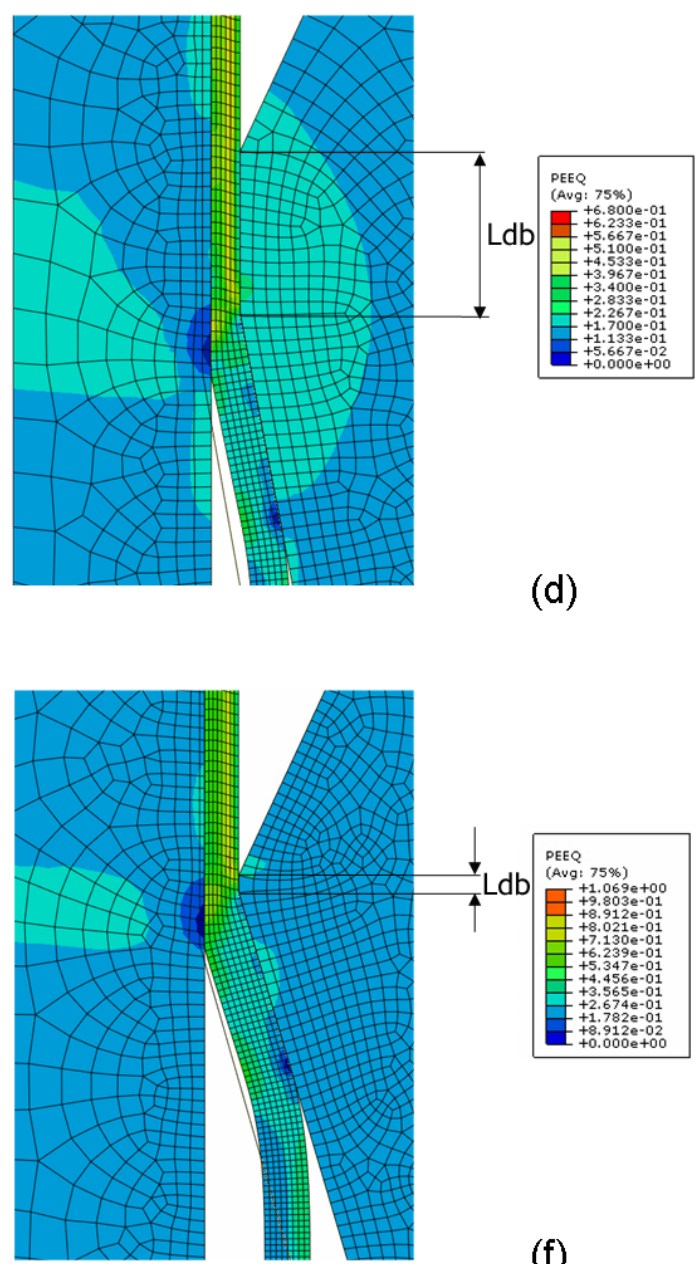

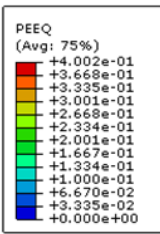

(b)
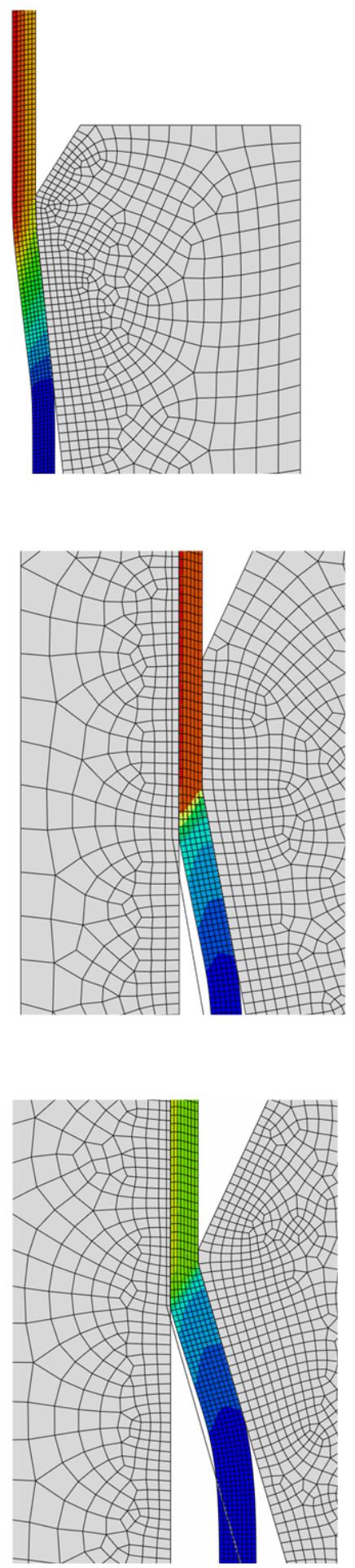

Figure 12: Maximum principal stress map (MPa) for test numbers (a) 4 (c) 7 (e) 9; and plastic equivalent strain map for test numbers (b) 4 (d) 7 (f) 9, for one hollow sinking (a and b) and two mandrel drawings (c to f) realised with the previously fitted parameters. 


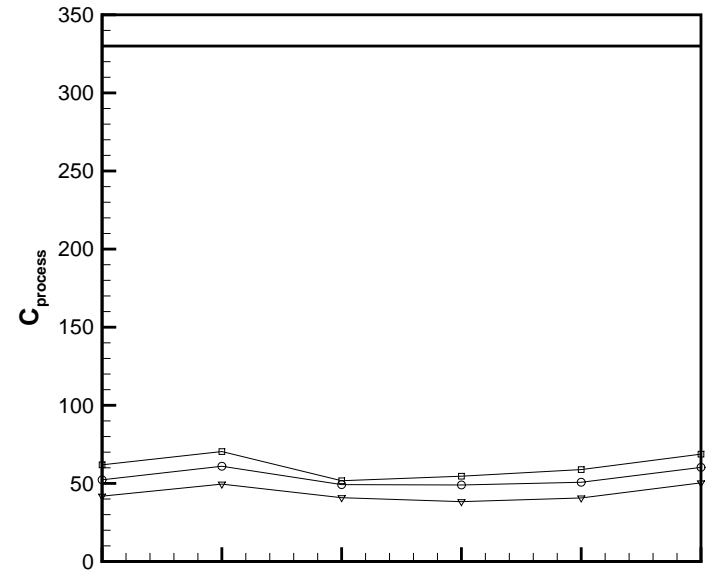

(a)

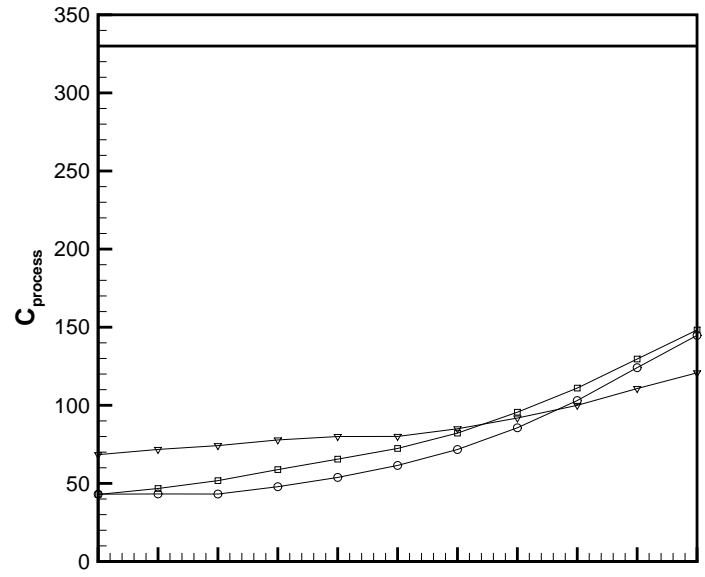

(b) Exterior of the tube ------------ interior of the tube

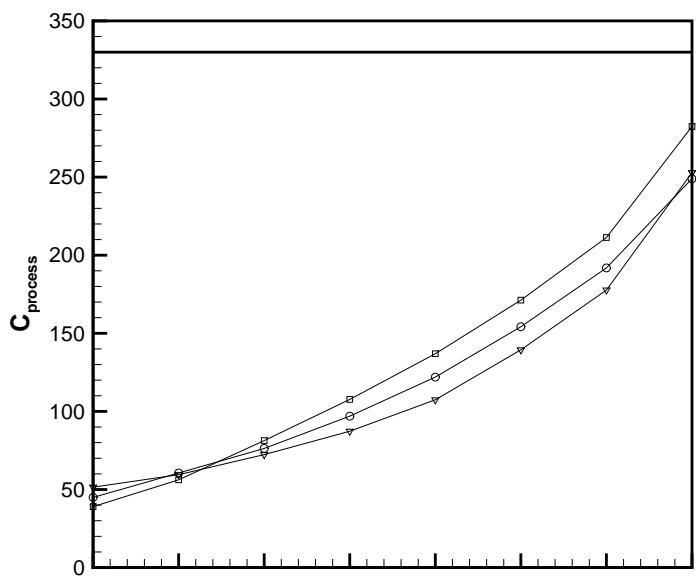

(c) Exterior of the tube ----------- interior of the tube

Figure 13: Evolution of the forming limit, along the tube thickness for the three different drawing types : (a) hollow sinking (tests 4-5-6), (b) mandrel sinking with a long die bearing (tests 7-8), and (c) mandrel drawing with a short die bearing (tests 9-10-11). For each test, three different values of the friction coefficient $(-\nabla-) 0.03,(-\circ-) 0.07$ and $(-\square-) 0.11$ were tested. The horizontal thick curves $(-)$ show the limit criterion identified during an uniaxial tensile test. 